\title{
Protective effects of parecoxib on rat primary astrocytes from oxidative stress induced by hydrogen peroxide ${ }^{* \#}$
}

\author{
Yun-zhi LING ${ }^{\S 1}$, Xiao-hong $\mathrm{LI}^{\S 1}$, Li YU ${ }^{\dagger 2}$, Ye ZHANG ${ }^{\dagger 3}$, \\ Qi-sheng LIANG ${ }^{1}$, Xiao-di YANG ${ }^{4}$, Hong-tao $\mathrm{WANG}^{5}$ \\ ( ${ }^{I}$ Department of Anesthesiology, First Affiliated Hospital of Bengbu Medical College, Bengbu 233004, China) \\ ( ${ }^{2}$ Department of Laboratory Medicine, Bengbu Medical College, Bengbu 233030, China) \\ ( ${ }^{3}$ Department of Anesthesiology, Second Affiliated Hospital of Anhui Medical University, Hefei 230601, China) \\ $\left({ }^{4}\right.$ Department of Parasitology, Bengbu Medical College, Bengbu 233030, China) \\ ( ${ }^{5}$ Department of Immunology, Bengbu Medical College, Bengbu 233030, China) \\ †E-mail: yuli95@163.com; zhang_ye011@163.com \\ Received Jan. 16, 2016; Revision accepted Apr. 10, 2016; Crosschecked Aug. 18, 2016
}

\begin{abstract}
Objective: To investigate the protective effects of parecoxib from oxidative stress induced by hydrogen peroxide $\left(\mathrm{H}_{2} \mathrm{O}_{2}\right)$ in rat astrocytes in vitro. Methods: All experiments included 4 groups: (1) negative control (NC) group, without any treatment; (2) $\mathrm{H}_{2} \mathrm{O}_{2}$ treatment group, $100 \mu \mathrm{mol} / \mathrm{L} \mathrm{H}_{2} \mathrm{O}_{2}$ treatment for $24 \mathrm{~h}$; (3) and (4) parecoxib pretreatment groups, 80 and $160 \mu \mathrm{mol} / \mathrm{L}$ parecoxib treatment for $24 \mathrm{~h}$, respectively, and then treated with $100 \mu \mathrm{mol} / \mathrm{L}$ $\mathrm{H}_{2} \mathrm{O}_{2}$. Several indices were investigated, and the expressions of $\mathrm{Bax}, \mathrm{Bcl}-2$, and brain-derived neurotrophic factor (BDNF) were quantified. Results: Compared to the NC group, exposure to $\mathrm{H}_{2} \mathrm{O}_{2}$ resulted in significant morphological changes, which could be reversed by pretreatment of parecoxib. In addition, $\mathrm{H}_{2} \mathrm{O}_{2}$ treatment led to loss of viability $(P=0.026)$ and increased intracellular reactive oxygen species $(R O S)$ levels $(P<0.001)$, and induced apoptosis $(P<0.01)$ in the primary astrocytes relative to the NC group. However, in the parecoxib pretreatment groups, all the above changes reversed significantly $(P<0.05)$ as compared to the $\mathrm{H}_{2} \mathrm{O}_{2}$ treatment group, and were nearly unchanged when compared to the NC group. Mechanical investigation showed that dysregulated Bax, Bcl-2, and BDNF could be implicated in these changes. Conclusions: Our results indicated that parecoxib provided a protective effect from oxidative stress induced by exposure to $\mathrm{H}_{2} \mathrm{O}_{2}$.
\end{abstract}

Key words: Parecoxib, Primary astrocyte, Hydrogen peroxide $\left(\mathrm{H}_{2} \mathrm{O}_{2}\right)$, Brain-derived neurotrophic factor (BDNF), Bax, $\mathrm{Bcl}-2$

http://dx.doi.org/10.1631/jzus.B1600017

CLC number: R965

\footnotetext{
${ }^{\ddagger}$ Corresponding authors

$\S$ The two authors contributed equally to this work

* Project supported by the Anhui Education Department (No. KJ2015B004by) and the Bengbu Medical College Innovation Grant (No. BYKY1424ZD), China

\# Electronic supplementary materials: The online version of this article (http://dx.doi.org/10.1631/jzus.B1600017) contains supplementary materials, which are available to authorized users

(1D) ORCID: Ye ZHANG, http://orcid.org/0000-0001-6328-8003

(C) Zhejiang University and Springer-Verlag Berlin Heidelberg 2016
}

\section{Introduction}

Elderly patients undergoing surgical intervention often suffer from postoperative cognitive dysfunction (POCD), a condition characterized by progressive deterioration of their cognitive function. POCD can markedly delay postoperative recovery and increase social, financial, and medical burdens. In addition, persistent POCD could develop into dementia, and even lead to the mortality of the patients (Arora et al., 2014). POCD can be diagnosed by 
comparing pre- and postoperative psychological parameters using psychometric tests. Though POCD has been observed for several decades, the pathogenesis of POCD remains largely unknown.

It has been widely accepted that, apart from the triggering factor of surgery, many factors contribute to the considerable risks associated with POCD, including old age, pre-existing cerebral, cardiac, and vascular diseases, alcohol abuse, low educational level, and intra- and postoperative complications (Rundshagen, 2014). Oxidative stress is described as a disturbed balance between the generation and elimination of reactive oxygen species (ROS) and reactive nitrogen species (RNS) (Yu et al., 2015; Pruchniak et al., 2016), in which condition, antioxidant defense system of the cells cannot coordinate with the increasing ROS and therefore cytotoxicity occurs.

Several sources of evidence indicated that astrocyte is closely implicated with the cognitive function, especially in neurodegenerative diseases with cognitive dysfunction, including Alzheimer and POCD (Phillips et al., 2014; Kim et al., 2015; Hernandez et al., 2016). During the early stages of POCD, astrocytes were abnormally activated and proliferated, which then released a variety of inflammatory cytokines, including interleukin-1 (IL-1), IL-6, and tumor necrosis factor (TNF), and the pro-growth factor S100. These cytokines may lead to pathological changes and repeated neural immune response in the brain, accelerating the deposition of neurotoxic $\beta$-amyloid peptide $(\mathrm{A} \beta)$ and the formation of neurofibrillary tangles. Neuronal damage and loss may finally lead to cognitive dysfunction in patients (Li et al., 2013; Jin et al., 2014). Oxidative stress plays a crucial role in the progress of POCD, in which free radicals attack astrocytes and neurons and sustain the above mentioned pathological changes of the neurons. Supporting the involvement of oxidative stress in POCD, Li et al. (2015) performed protein expression profiling analysis of the hippocampus to explore the different proteins between normal control aged rats and aged rats with POCD, and found that oxidative stressrelated pathways were dysregulated in POCD. An et al. (2013) also reported that oxidative stress, as well as increased iron accumulation, might be involved in the pathogenesis of POCD. However, the underlying molecular pathways associated with oxidative stress in POCD remain largely unknown.
Parecoxib, a nonsteroidal anti-inflammatory drug (NSAID), selectively blocks off the actions of cyclooxygenase 2 (COX-2) enzyme, which was widely used for postoperative pain relief in clinical practice (Lu et al., 2015). Moreover, Salloum et al. (2009) showed that parecoxib could inhibit apoptosis in acute myocardial infarction. In this present study, we used the hydrogen peroxide $\left(\mathrm{H}_{2} \mathrm{O}_{2}\right)$ exposure method to induce oxidative stress in primary astrocyte and investigated the functions of parecoxib on oxidative stress.

\section{Materials and methods}

\subsection{Primary astrocyte culture}

Primary astrocytes were obtained from Sprague Dawley rats (1 to $7 \mathrm{~d}$ old). All experiments were approved and supervised by the Institutional Animal Care and Use Committee of the First Affiliated Hospital of Bengbu Medical College (Bengbu, China). All efforts were made to minimize animal suffering and to reduce the number of animals used.

To prepare primary astrocytes, the hippocampus tissue was first aseptically dissected. After removing the meninges, the hippocampus tissue was mechanically scattered in D-Hank's balanced salt solution (Gibco, USA). Then, the hippocampus tissue was digested with $0.05 \%(0.5 \mathrm{~g} / \mathrm{L})$ trypsin at $37{ }^{\circ} \mathrm{C}$ for $10 \mathrm{~min}$, followed by digestion termination using a certain volume of Dulbecco's modified Eagle medium/ Ham's F-12 medium (DMEM/F12; Gibco, USA). Finally, the cell supernates were filtered through a 200-mesh metal filter at $400 \mathrm{~g}$ for $5 \mathrm{~min}$.

All cells were cultured in DMEM/F12 supplemented by a $10 \%$ fetal bovine serum (FBS), $2 \mathrm{mmol} / \mathrm{L}$ glutamine, $100 \mathrm{U} / \mathrm{ml}$ penicillin, and $100 \mathrm{mg} / \mathrm{ml}$ streptomycin under the stable atmosphere of $37^{\circ} \mathrm{C}$, $95 \%$ air $/ 5 \% \mathrm{CO}_{2}$ and then saturation in humidity. Oligodendrocytes and microglia were removed by shaking the dishes at $260 \mathrm{r} / \mathrm{min}$ overnight and following that with medium exchange. The purity of the primary astrocyte cultures was determined by immunofluorescence using an antibody against glial fibrillary acidic protein (GFAP), an astrocyte-specific marker.

For all experiments, when the primary astrocytes reached confluence on the plate, they were removed 
with $0.25 \%$ trypsin, diluted with $\mathrm{DMEM} / \mathrm{F} 12$, and replated into 6-well plates for serial subcultivation. All experiments were carried out when cells nearly reached confluence during the 4 th to 7 th passages.

\section{2 $\mathrm{H}_{2} \mathrm{O}_{2}$ and parecoxib treatments of primary astrocytes}

After the characterization of the astrocyte cultures from newly-born rats, we combined biochemical and morphological tools to explore the responses of the cells to different stimuli. All experiments included 4 groups: (1) negative control (NC) group, without any treatment; (2) $\mathrm{H}_{2} \mathrm{O}_{2}$ treatment group, primary astrocytes were treated with $100 \mu \mathrm{mol} / \mathrm{L}$ $\mathrm{H}_{2} \mathrm{O}_{2}$ for $24 \mathrm{~h}$; (3) and (4) parecoxib pretreatment groups, cells were pretreated with 80 and $160 \mu \mathrm{mol} / \mathrm{L}$ parecoxib for $24 \mathrm{~h}$, respectively, and then treated with $100 \mu \mathrm{mol} / \mathrm{L} \mathrm{H}_{2} \mathrm{O}_{2}$. Parecoxib (Cat. No. 32152, SigmaAldrich, USA) was diluted to $10 \mathrm{mmol} / \mathrm{L}$ using a serum-free DMEM/F12 medium and then stored at $-20^{\circ} \mathrm{C}$ for future use. Before each usage, $10 \mathrm{mmol} / \mathrm{L}$ parecoxib was diluted to a final concentration of 80 or $160 \mu \mathrm{mol} / \mathrm{L}$ using a serum-free DMEM/F12 medium. During treatment, primary astrocytes were cultured in the normal atmosphere $\left(37^{\circ} \mathrm{C}, 95 \%\right.$ air $/ 5 \% \mathrm{CO}_{2}$, and saturated in humidity).

After these treatments, the primary astrocytes were observed and photographed using an inverted optical microscope (Leica, Germany) and then stained with Wright stain to examine any morphological changes.

\subsection{Viability assay}

To assess the metabolic activity, methylthiazolyldiphenyl-tetrazolium bromide (MTT) assay (SigmaAldrich, USA) was performed in accordance with the manufacturer's instructions. Briefly, primary astrocytes were collected and plated at a density of 5000 cells/well in a $96-w e l l$ culture dish. Twenty-four hours later, the medium was discarded and the cells were fixed by using methanol. Then, a total of $20 \mu \mathrm{l}$ of MTT solution at $5 \mathrm{mg} / \mathrm{ml}$ was added into each well. After being incubated at $37^{\circ} \mathrm{C}$ for $4 \mathrm{~h}$, the MTT solution was replaced by $200 \mu \mathrm{l}$ of dimethyl sulfoxide (DMSO, Sigma-Aldrich, USA), which was used to dissolve the formazan crystals through dark incubation for $10 \mathrm{~min}$. Absorbance at $570 \mathrm{~nm}$ was measured and the growth inhibition rate was calculated with the following formula: inhibition rate $=\left(1-A_{\text {exp }} / A_{\text {con }}\right) \times$ $100 \%$, where $A_{\exp }$ and $A_{\text {con }}$ are the average absorbances of the experimental and control groups, respectively. Three independent experiments were performed for each sample.

\subsection{Fluorescence measurement of intracellular reactive oxygen species}

Intracellular peroxides were measured by using an oxidation-sensitive fluorescence probe, 2',7'dichlorodihydrofluorescein diacetate (DCDHF-DA). In brief, the medium was washed twice with phosphate buffered saline (PBS) and the primary astrocytes were incubated, with $10 \mu \mathrm{mol} / \mathrm{L}$ DCDFH-DA for $20 \mathrm{~min}$ at $37^{\circ} \mathrm{C}$, in the dark. After removal of the DCDFH-DA, the fluorescence intensities at $488 \mathrm{~nm}$ of excitation wave and $525 \mathrm{~nm}$ of emission wave were monitored by flow cytometry and the mean fluorescence intensity of 10000 cells was used to represent the amount of ROS.

\subsection{Cell apoptosis assay}

Cell apoptosis assays were performed through flow cytometry using propidium iodide (PI) staining (Sigma-Aldrich, USA). The detailed procedures were observed in previous studies (Shen et al., 2015). Briefly, the primary astrocytes were collected, including both floating and attached cells, and then resuspended in $70 \%$ pre-cooled ethanol at $4{ }^{\circ} \mathrm{C}$ for fixing for more than $24 \mathrm{~h}$. Before flow cytometry, the fixed cells were washed and stained with PI solution $(50 \mu \mathrm{g} / \mathrm{ml}$ PI and $25 \mu \mathrm{g} / \mathrm{ml} \mathrm{RNase})$ at $37{ }^{\circ} \mathrm{C}$ for $30 \mathrm{~min}$ in the dark. Stained cells were measured by fluorescence-activated cell sorting (FACS) using flow cytometry analysis.

\subsection{Reverse transcription polymerase chain reac- tion (RT-PCR)}

Total RNA was extracted from the primary astrocytes using a TRIzol reagent (Invitrogen, USA). The purity and concentration of the total RNA were determined at $260 \mathrm{~nm} / 280 \mathrm{~nm}$ using spectrophotometry. Complementary DNA was synthesized using a total RNA reverse transcription kit according to the manufacturer's protocol (Tiangen, China). Approximately $1 \mu \mathrm{g}$ of total RNA was reverse-transcribed in a reaction volume of $20 \mu \mathrm{l}$. PCR reaction cycling conditions were performed as follows: $94{ }^{\circ} \mathrm{C}$ for $2 \mathrm{~min}$, 
followed by 35 cycles of denaturation at $94{ }^{\circ} \mathrm{C}$ for $30 \mathrm{~s}$, annealing at $62^{\circ} \mathrm{C}(\mathrm{Bcl}-2)$ or $58^{\circ} \mathrm{C}(\mathrm{Bax})$ for $30 \mathrm{~s}$, and extension at $72{ }^{\circ} \mathrm{C}$ for $30 \mathrm{~s}$, and a single extension at $72{ }^{\circ} \mathrm{C}$ for $5 \mathrm{~min}$. The primer sequences were as follows: (1) Bax, forward 5'-CCA AGA AGC TGA GCG AGT GTC-3', reverse 5'-TGA GGA CTC CAG CCA CAA AGA-3'; (2) Bcl-2, forward 5'-CAA GCC GGG AGA ACA GGG TA-3', reverse 5'-CCC ACC GAA CTC AAA GAA GGC-3'; (3) $\beta$-actin, forward 5'-TCA TGA AGT GTG ACG TTG ACA TCC GT-3', reverse 5'-CCT AGA AGC ATT TGC GGT GCA CGA TG-3'. Product sizes for Bax, Bcl-2, and $\beta$-actin were 377, 450, and $285 \mathrm{bp}$, respectively. The PCR products were electrophoresed in $1 \%(0.01 \mathrm{~g} / \mathrm{ml})$ agarose gel, stained with ethidium bromide, examined under UV light, scanned, and photographed. The signal intensities were determined by using Tanon imaging software (Tanon, China). Relative amounts of Bax and Bcl-2 mRNA expressions were measured by the signal intensity ratio of $\mathrm{Bax}$ and $\mathrm{Bcl}-2$ to $\beta$-actin, respectively.

\subsection{Western blot}

Western blot analysis was performed in accordance with previous studies (Jia et al., 2016). The dilution ratios for BDNF and $\beta$-actin were 1:1000 and 1:5000, respectively. Densitometric values were normalized using $\beta$-actin as an internal control.

\subsection{Statistical analysis}

All the statistical analyses were performed using GraphPad 5.0 software and Microsoft Excel. The data were expressed as mean \pm standard error of the mean (SEM), and the two-tailed Student's test was used for comparison of the two groups and a one-way analysis of variance (ANOVA) was applied to compare more than the two groups. $P<0.05$ was considered statistically significant.

\section{Results}

\subsection{Identification of primary astrocytes}

The purity of the primary astrocytes was determined by applying the immunofluorescence method using an anti-GFAP primary antibody. As shown in Fig. S1, the GFAP-positive cells (astrocytes) were approximately $95 \%$ of all cells. The cell bodies of the astrocytes were large and flat in the polygon or spindle and the cytoplasmic protuberances were bulky and interweaved with each other. In addition, the boundary of the astrocytes was clear.

\subsection{Parecoxib resisted morphological changes of the primary astrocytes due to exposure to $\mathrm{H}_{2} \mathrm{O}_{2}$}

Normally, primary astrocytes cultured in vitro showed regular and large cell bodies in the polygon or spindle, and also clear cell boundaries. More importantly, the cells were vibrant (Fig. 1a). However, when they were treated with $100 \mu \mathrm{mol} / \mathrm{L} \mathrm{H}_{2} \mathrm{O}_{2}$, the cell morphology changed sharply, with shrinking cell bodies and blurry edges (Fig. 1b). We further pretreated the primary astrocytes with parecoxib before $\mathrm{H}_{2} \mathrm{O}_{2}$ treatment, in order to investigate the protective effect of parecoxib from oxidative stress induced by $\mathrm{H}_{2} \mathrm{O}_{2}$. From Fig. 1c $(80 \mu \mathrm{mol} / \mathrm{L}$ parecoxib $)$ and Fig. 1d (160 $\mu \mathrm{mol} / \mathrm{L}$ parecoxib), we found that if the primary astrocytes were pretreated with parecoxib, cell morphology changed mildly after $\mathrm{H}_{2} \mathrm{O}_{2}$ treatment, suggesting that parecoxib had an obvious protective effect from oxidative stress induced by $\mathrm{H}_{2} \mathrm{O}_{2}$.

3.3 $\mathrm{H}_{2} \mathrm{O}_{2}$ exposure led to loss of viability of the primary astrocytes, which was reversed by parecoxib

In order to investigate the effect of $\mathrm{H}_{2} \mathrm{O}_{2}$ exposure on astrocyte's viability, we treated cells with $100 \mu \mathrm{mol} / \mathrm{L} \mathrm{H}_{2} \mathrm{O}_{2}$ and applied the MTT method to measure the growth inhibition rate of the astrocytes. Compared to the $\mathrm{NC}$ group, the groups treated with $\mathrm{H}_{2} \mathrm{O}_{2}$ showed a $(35.25 \pm 0.42) \%$ reduction of viability $(P=0.026$; Fig. 2). However, if the astrocytes were pretreated with parecoxib, the loss of astrocyte's viability could be reversed by both $80 \mu \mathrm{mol} / \mathrm{L}(P=0.038)$ and $160 \mu \mathrm{mol} / \mathrm{L}(P=0.031)$ parecoxib relative to the $\mathrm{H}_{2} \mathrm{O}_{2}$ treatment group (Fig. 2).

\subsection{Protection of parecoxib from the increase of intracellular ROS levels of primary astrocytes due to exposure to $\mathrm{H}_{2} \mathrm{O}_{2}$}

To investigate whether $\mathrm{H}_{2} \mathrm{O}_{2}$ exposure influenced the intracellular ROS levels and the potential protective effect of parecoxib from $\mathrm{H}_{2} \mathrm{O}_{2}$ exposure in primary astrocytes, we treated primary astrocytes with $\mathrm{H}_{2} \mathrm{O}_{2}$ and parecoxib in different concentrations and measured the intracellular peroxides using DCDHF-DA. 
(a)

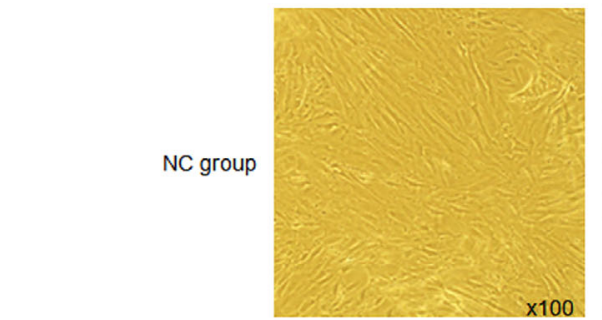

(c) Parecoxib pretreatment group $(80 \mu \mathrm{mol} / \mathrm{L})$

(d) Parecoxib pretreatment group (160 $\mu \mathrm{mol} / \mathrm{L})$

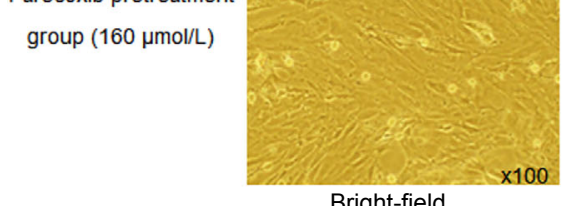

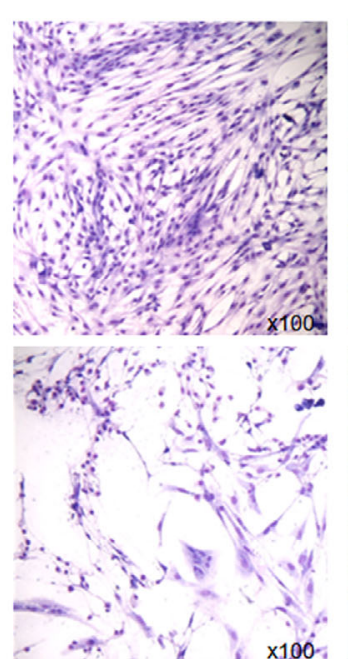
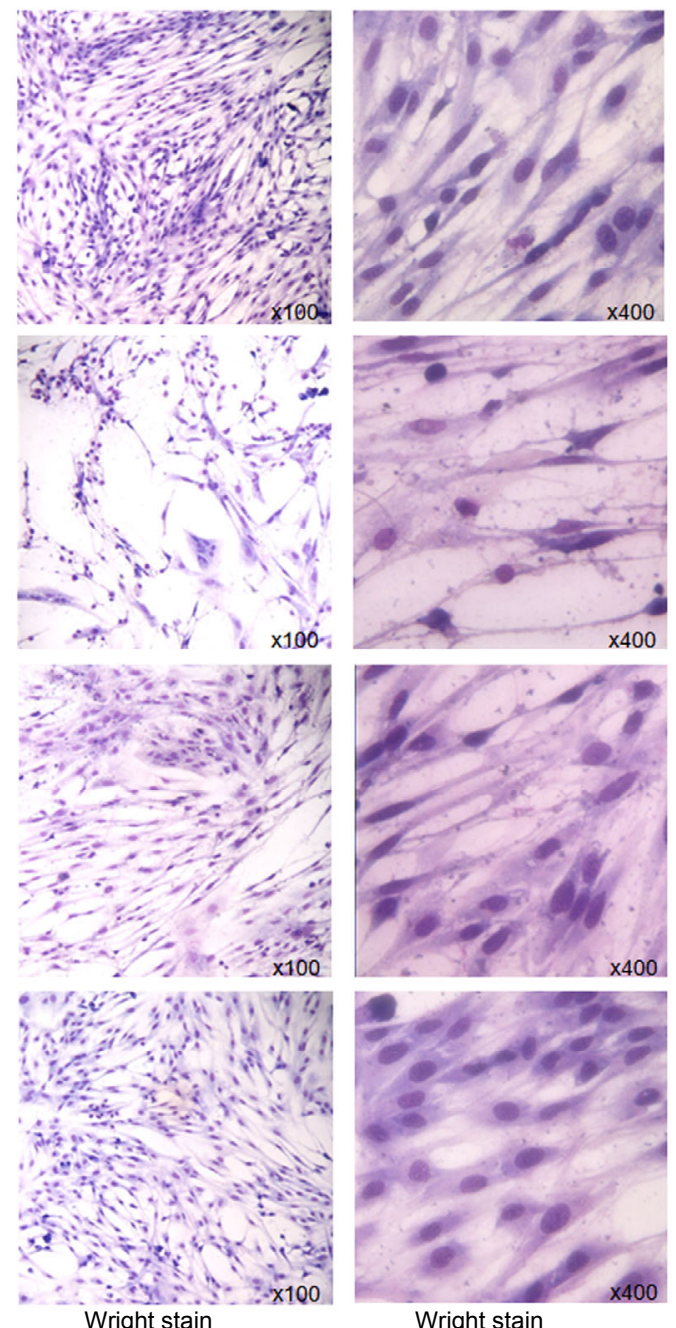

Fig. 1 Parecoxib resisted morphological changes of the primary astrocytes due to exposure to $\mathrm{H}_{2} \mathrm{O}_{2}$ (a) $\mathrm{NC}$ group; (b) $\mathrm{H}_{2} \mathrm{O}_{2}$ treatment group $(100 \mu \mathrm{mol} / \mathrm{L})$; (c) Parecoxib pretreatment group $(80 \mu \mathrm{mol} / \mathrm{L})$; (d) Parecoxib pretreatment group $(160 \mu \mathrm{mol} / \mathrm{L})$

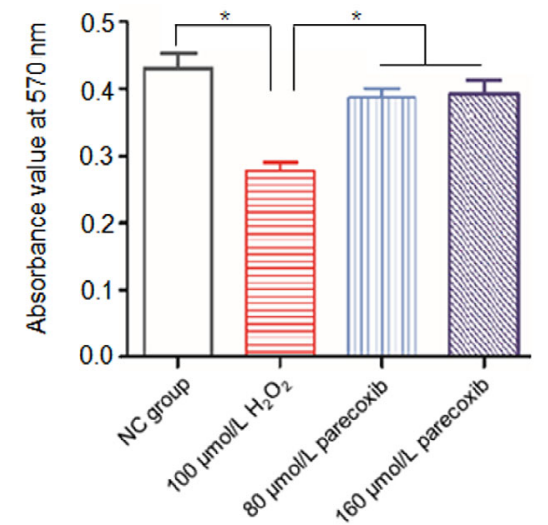

Fig. $2 \mathrm{H}_{2} \mathrm{O}_{2}$ exposure led to loss of viability in the primary astrocytes, which was reversed by parecoxib Data shown were representative of three independent experiments and error bars represent mean \pm SEM. ${ }^{*} P<0.05$ vs. $\mathrm{H}_{2} \mathrm{O}_{2}$ treatment group
When compared to the NC group, the fluorescence intensity of the $\mathrm{H}_{2} \mathrm{O}_{2}$ treatment group increased significantly $(P<0.001)$, suggesting strengthened ROS levels. However, if the primary astrocytes were pretreated with parecoxib $(160 \mu \mathrm{mol} / \mathrm{L})$ and then exposed to $100 \mu \mathrm{mol} / \mathrm{L}_{2} \mathrm{O}_{2}$, the fluorescence intensity decreased significantly relative to the $\mathrm{H}_{2} \mathrm{O}_{2}$ treatment group $(P<0.01)$, and more closer to the $\mathrm{NC}$ group $(P>0.05)$ (Fig. 3). For the $80 \mu \mathrm{mol} / \mathrm{L}$ pretreatment group, the fluorescence intensity also decreased relative to the $\mathrm{H}_{2} \mathrm{O}_{2}$ treatment group, but not reaching statistical significance, and significant differences of fluorescence intensity existed between the $80 \mu \mathrm{mol} / \mathrm{L}$ pretreatment group and the $\mathrm{NC}$ group as well. 
(a)

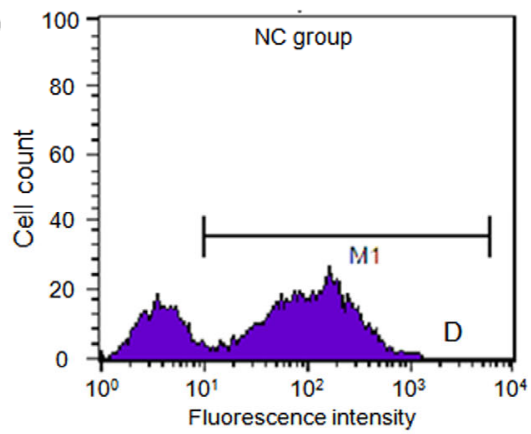

(c)

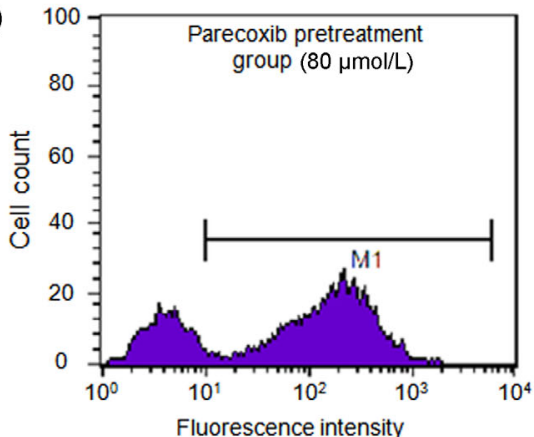

(e)

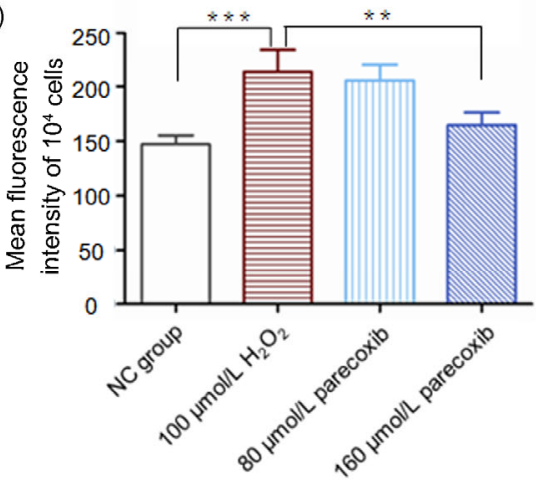

(b)

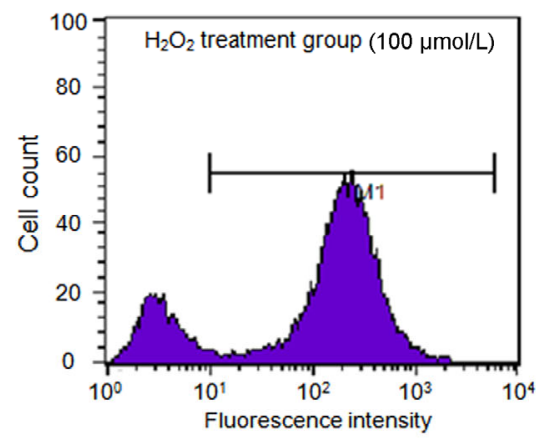

(d)

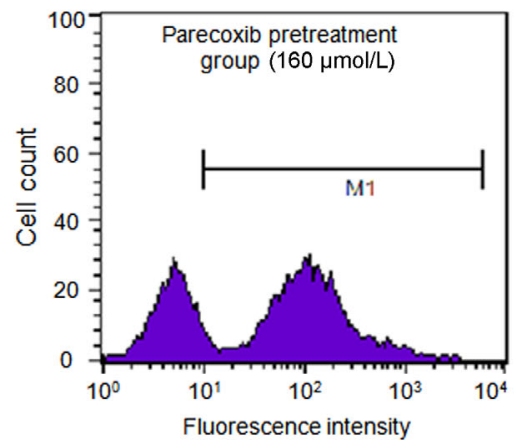

Fig. 3 Protection of parecoxib from the increase of the intracellular ROS levels of the primary astrocytes due to exposure to $\mathrm{H}_{2} \mathrm{O}_{2}$

Intracellular peroxides of the primary astrocytes were indicated by fluorescence intensity in the NC group (a), $\mathrm{H}_{2} \mathrm{O}_{2}(100 \mu \mathrm{mol} / \mathrm{L})$ treatment group (b), parecoxib (80 $\mu \mathrm{mol} / \mathrm{L})$ pretreatment group (c), and parecoxib (160 $\mu \mathrm{mol} / \mathrm{L})$ pretreatment group (d). (e) Mean intracellular fluorescence intensity of the $10^{4}$ cells. Data shown were representative of three independent experiments and the error bars represent the mean \pm SEM. ${ }^{* *} P<0.01,{ }^{* * *} P<0.001$ vs. $\mathrm{H}_{2} \mathrm{O}_{2}$ treatment group

decreased relative to the $\mathrm{H}_{2} \mathrm{O}_{2}$ treatment group $(P<0.01)$ and were comparative with the $\mathrm{NC}$ group $(P>0.05)$ (Fig. 4).

To further explore the apoptosis-induced effect of $\mathrm{H}_{2} \mathrm{O}_{2}$ on the primary astrocyte and the rescued effect of parecoxib from $\mathrm{H}_{2} \mathrm{O}_{2}$ exposure, we assessed the extent of cell apoptosis through flow cytometry using PI staining.

The $\mathrm{H}_{2} \mathrm{O}_{2}$ induced strong cell apoptosis of the primary astrocytes at the concentration of $100 \mu \mathrm{mol} / \mathrm{L}$, compared to the $\mathrm{NC}$ group $(34.0 \%$ vs. $9.1 \%, P<0.01)$. However, if the primary astrocytes were pretreated with parecoxib ( 80 and $160 \mu \mathrm{mol} / \mathrm{L}$ ) and then exposed to $100 \mu \mathrm{mol} / \mathrm{L} \mathrm{H}_{2} \mathrm{O}_{2}$, the apoptotic rates were $16.5 \%$ and $14.6 \%$, respectively, which were significantly

\subsection{Exposure to $\mathrm{H}_{2} \mathrm{O}_{2}$ resulted in dysregulated} $B a x, B c l-2$, and $B D N F$ expressions, which were reversed by parecoxib

In order to explore the possible mechanisms of $\mathrm{H}_{2} \mathrm{O}_{2}$-induced apoptosis, we performed RT-PCR to quantify the expression levels of $B a x$ and $B c l-2$, both of which were implicated in cell apoptosis in previous studies (Guan et al., 2015; Cao et al., 2016).

Compared to the $\mathrm{NC}$ group, the relative expressions of Bax and Bcl-2 in the $\mathrm{H}_{2} \mathrm{O}_{2}$ treatment group 
(a)

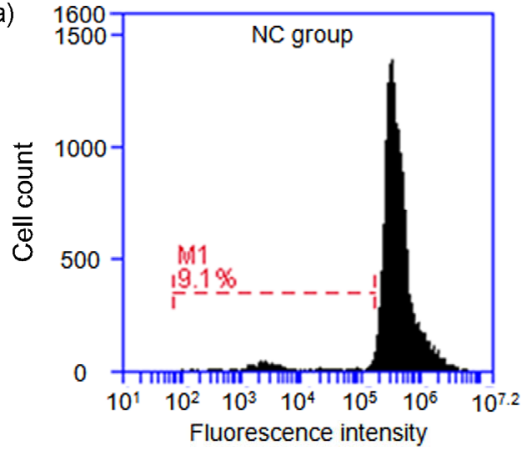

(c)

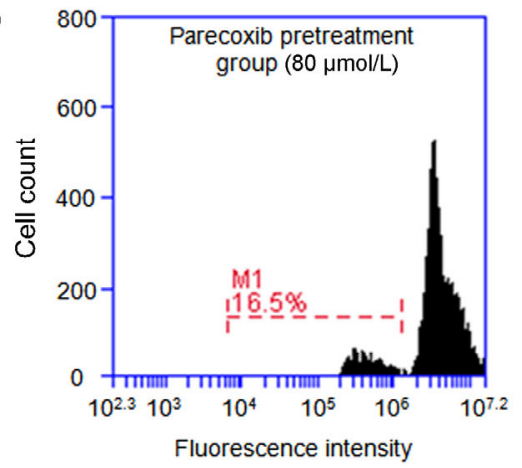

(e)

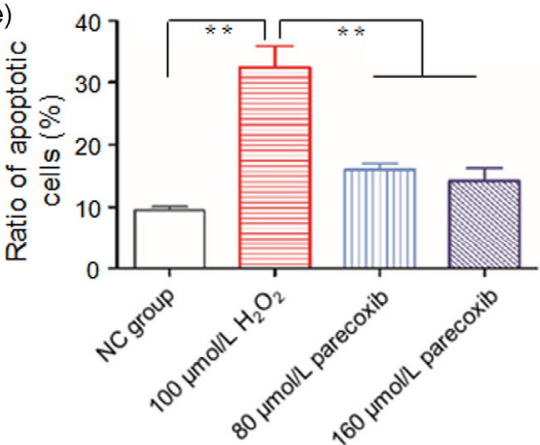

were significantly increased $(P=0.012)$ and decreased $(P=0.038)$, respectively. In the $160 \mu \mathrm{mol} / \mathrm{L}$ parecoxib pretreatment group, the Bax relative expression showed significantly downregulation relative to the $\mathrm{H}_{2} \mathrm{O}_{2}$ treatment group $(P=0.010)$, and the $B c l-2$ relative expression was statistically upregulated $(P=$ $0.037)$. For the $80 \mu \mathrm{mol} / \mathrm{L}$ parecoxib pretreatment group, the relative Bax expression was downregulated and the relative $B c l-2$ was upregulated as well, but not reaching statistical significance, as compared to the $\mathrm{H}_{2} \mathrm{O}_{2}$ treatment group (Fig. 5).

We also performed the Western blot analysis to quantify the expression levels of $B D N F$. Compared to the $\mathrm{NC}$ group, the BDNF expression was significantly
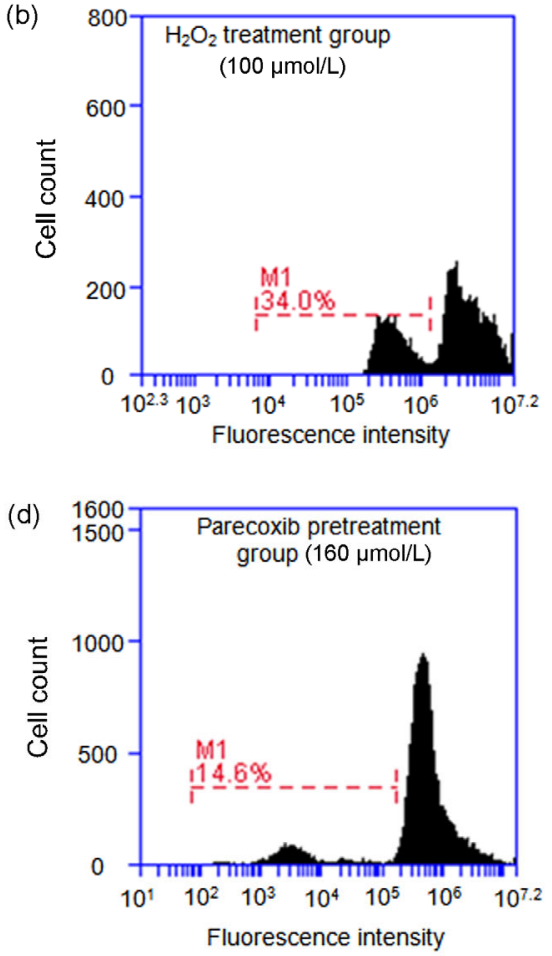

Fig. 4 Parecoxib resisted apoptosis of the primary astrocytes induced by exposure to $\mathrm{H}_{2} \mathrm{O}_{2}$

Cell apoptosis was indicated through flow cytometry using propidium iodide (PI) staining in the $\mathrm{NC}$ group (a), $\mathrm{H}_{2} \mathrm{O}_{2}(100 \mu \mathrm{mol} / \mathrm{L})$ treatment group (b), parecoxib $(80 \mu \mathrm{mol} / \mathrm{L})$ pretreatment group (c), and parecoxib (160 $\mu \mathrm{mol} / \mathrm{L})$ pretreatment group (d). (e) Ratio of apoptotic cells in four groups. Data shown were representative of three independent experiments and the error bars represent the mean \pm SEM. ${ }^{* *} P<0.01$ vs. $\mathrm{H}_{2} \mathrm{O}_{2}$ treatment group

decreased $(P=0.012)$. If cells were pretreated by $160 \mu \mathrm{mol} / \mathrm{L}$ parecoxib, the $B D N F$ level could be upregulated relative to the $\mathrm{H}_{2} \mathrm{O}_{2}$ treatment group $(P=$ 0.018) (Fig. 6).

\section{Discussion}

In the present study, we tried to investigate the protective effect of parecoxib from adverse conditions derived from oxidative stress induced by $\mathrm{H}_{2} \mathrm{O}_{2}$ exposure in primary astrocytes. We observed that $\mathrm{H}_{2} \mathrm{O}_{2}(100 \mu \mathrm{mol} / \mathrm{L})$ exposure led to loss of viability, morphological changes, increased intracellular ROS 

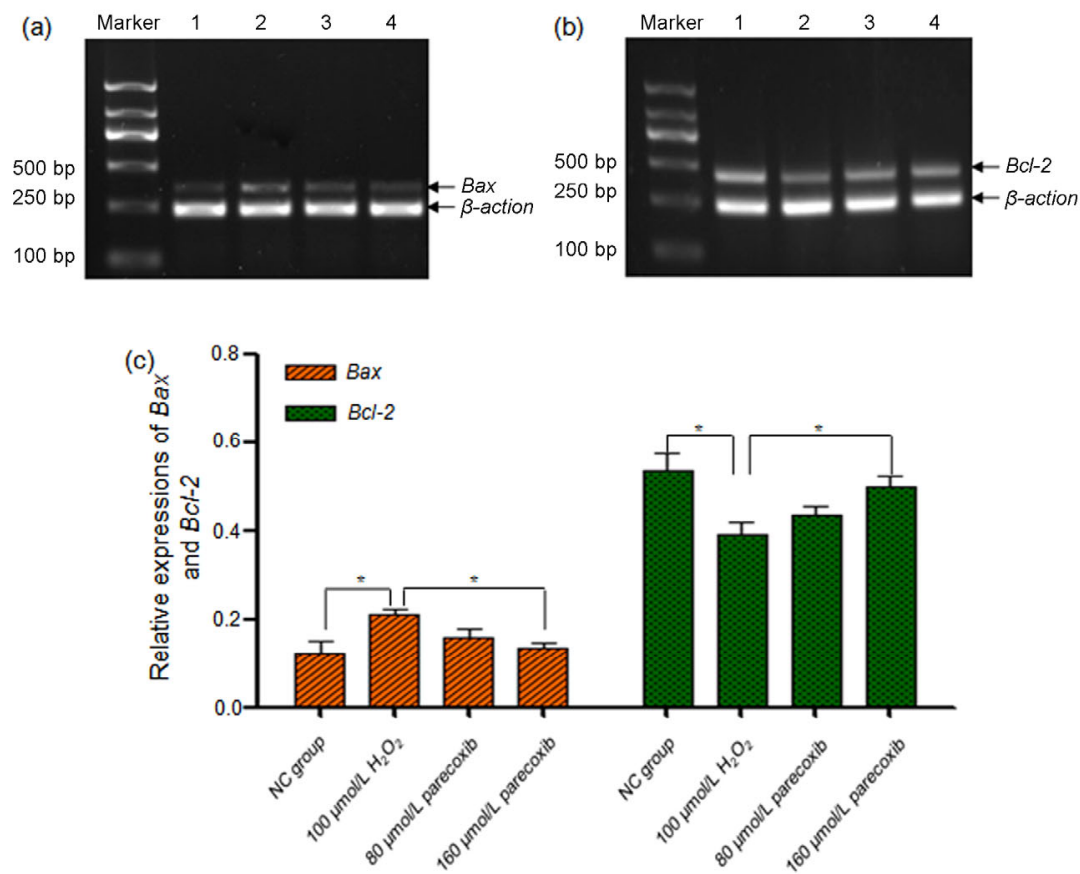

Fig. 5 Exposure to $\mathrm{H}_{2} \mathrm{O}_{2}$ resulted in dysregulated $\mathrm{Bax}$ and $\mathrm{Bcl}-2$ expressions, which were reversed using parecoxib (a, b) Gel electrophoresis images of the RT-PCR products of Bax and Bcl-2 in four groups: (1) NC group; (2) $\mathrm{H}_{2} \mathrm{O}_{2}(100 \mu \mathrm{mol} / \mathrm{L})$ treatment group; (3) parecoxib $(80 \mu \mathrm{mol} / \mathrm{L})$ pretreatment group; and (4) parecoxib $(160 \mu \mathrm{mol} / \mathrm{L})$ pretreatment group. $\beta$-Actin was used as an internal control. The RT-PCR product lengths of Bax, Bcl-2, and $\beta$-actin were 377, 450, and $285 \mathrm{bp}$, respectively. (c) Gray intensity of the gel electrophoresis images of the RT-PCR products of $\mathrm{Bax}$ and $\mathrm{Bcl}-2$ in four groups. Data shown were representative of three independent experiments and the error bars represent the mean \pm SEM. ${ }^{*} P<0.05$ vs. $\mathrm{H}_{2} \mathrm{O}_{2}$ treatment group
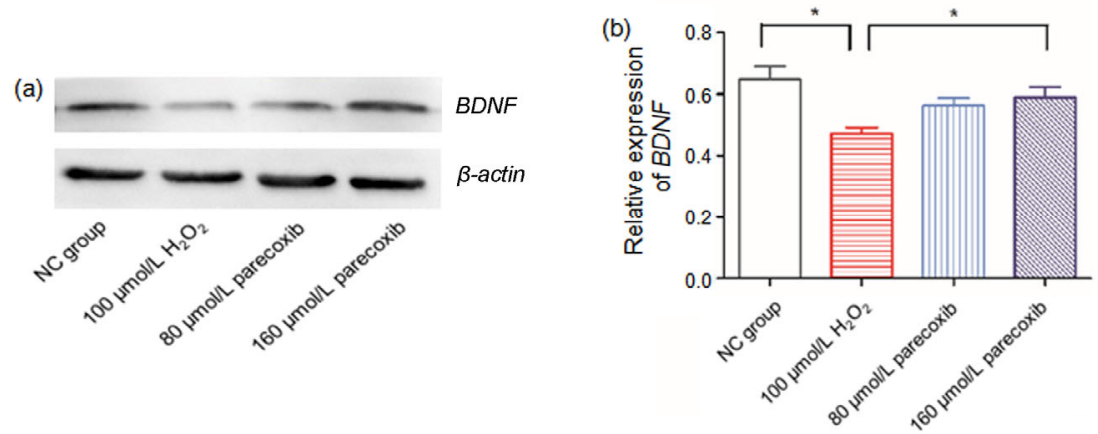

Fig. 6 Exposure to $\mathrm{H}_{2} \mathrm{O}_{2}$ resulted in dysregulated $B D N F$ expression, which was reversed by parecoxib Data shown were representative of three independent experiments and the error bars represent the mean \pm SEM. ${ }^{*} P<0.05$ vs. $\mathrm{H}_{2} \mathrm{O}_{2}$ treatment group. $\beta$-actin was used an internal control

levels, and apoptosis of the astrocytes cultured in vitro; however, pretreatment of 80 or $160 \mu \mathrm{mol} / \mathrm{L}$ parecoxib could reverse these conditions.

Glial cells account for approximately $90 \%$ of the total cells in the nervous system, among which astrocytes are one category representing the largest number. Previous studies showed that astrocytes not only are implicated in formation and maintenance of the blood-brain barrier, and the regulation of synaptic plasticity (Barres, 2008), but also provide energy and metabolic support for neurons (Pellerin et al., 2007).

Oxidative stress is described as the disturbed balance between generation and elimination of the ROS and RNS (Pruchniak et al., 2016), in which condition antioxidant defense system of the cells cannot coordinate with the increasing ROS and therefore cytotoxicity occurs. Several sources of evidence showed that oxidative stress plays an important 
role in the development of POCD (An et al., 2013; Li et al., 2015). In the present study, we show that exposure to $\mathrm{H}_{2} \mathrm{O}_{2}$ increased intracellular ROS levels of primary astrocytes, while pretreatment with parecoxib $(160 \mu \mathrm{mol} / \mathrm{L})$ could reverse the increased intracellular ROS levels.

Mechanical investigation of our study indicated that exposure to $\mathrm{H}_{2} \mathrm{O}_{2}$ resulted in the increase of $\mathrm{Bax}$ and decease of $\mathrm{BCl}-2$ expression levels, which were reversed by $160 \mu \mathrm{mol} / \mathrm{L}$ parecoxib pretreatment, suggesting that dysregulated $\mathrm{Bax}$ and $\mathrm{Bcl}-2$ could mediate oxidative stress induced by $\mathrm{H}_{2} \mathrm{O}_{2}$ exposure, and the protective effect of parecoxib in the primary astrocytes. Both Bax and Bcl-2 were reported to be implicated in cell apoptosis in previous studies (Guan et al., 2015; Cao et al., 2016). Bcl-2 is known to be a "survival gene" and its expression level is positively correlated with the cell life span. Zhang et al. (2014) have reported that Bcl-2 protein expressed early in the hippocampus in the transient cerebral ischemia animal experiments, exhibited a protective role from cerebral ischemia. Bax is a apoptosis promoting gene, which can induce apoptosis through initiating the mitochondrial permeability transition. In addition, Bax may activate cysteine protease and then antagonize the protective effect of Bcl-2 (Smith et al., 2015). Therefore, the expressions of $\mathrm{Bax}$ and $\mathrm{Bcl}-2$ could be inversely related, which are consistent with our study.

BDNF is one of the most abundant secretions of astrocytes, and has diverse functions in maintaining survival, development, regeneration, and differentiation of neurons. Valvassori et al. (2015) observed that BDNF treatment modulated the antioxidant enzymes, and protected the ouabain (OUA)-induced oxidative damage in the brain of rats. In addition, Takeda et al. (2013) showed that BDNF protected human microvascular endothelial cells from the toxicity of TNF- $\alpha$ through the regulation of the PTEN/Akt pathway. All the above evidence suggests that BDNF could play an important role in the protective effect of parecoxib in primary astrocytes. Indeed, we observed significantly downregulated $B D N F$ levels of primary astrocytes in the $\mathrm{H}_{2} \mathrm{O}_{2}$ treatment group when compared to the $\mathrm{NC}$ group; however, if cells were pretreated with parecoxib, the expression of $B D N F$ was statistically upregulated relative to the $\mathrm{H}_{2} \mathrm{O}_{2}$ treatment group. Nevertheless, the detailed molecular pathways of BDNF implicated in the protective function of parecoxib still remain to be identified.
One limitation of this study was that we used parecoxib, but not its secondary metabolite by hepatic enzyme in vivo, valdecoxib, for primary astrocyte treatment. Parecoxib is the first injectable COX-2 inhibitor and has been introduced into clinical practice for postoperative pain control since 2001. Compared to valdecoxib, the secondary metabolite by the hepatic enzyme in vivo, parecoxib is prescribed more prevalently in clinical practice. Based on clinical observation, we chose parecoxib, but not valdecoxib, for experimental research. However, since experiments in vitro cannot simulate the in vivo environment, for example, lack of the hepatic enzyme, parecoxib could exert its antalgic function only by itself, but not valdecoxib. This could confer functional divergence of parecoxib between in vitro and in vivo experiments to some extent. It would be essential to conduct in vivo replication of the present studies in the future.

In conclusion, our results indicated that parecoxib ( 80 and $160 \mu \mathrm{mol} / \mathrm{L}$ ) had a protective effect from oxidative stress induced by exposure to $\mathrm{H}_{2} \mathrm{O}_{2}$. Moreover, dysregulated $\mathrm{Bax}, \mathrm{Bcl}-2$, and $B D N F$ could be underpinning the pathological process.

\section{Acknowledgements}

We sincerely thank Dr. Shu-quan RAO (School of Life Science and Engineering, Southwest Jiaotong University, Chengdu, China) for providing technical guidance and statistic assistance.

\section{Compliance with ethics guidelines}

Yun-zhi LING, Xiao-hong LI, Li YU, Ye ZHANG, Qi-sheng LIANG, Xiao-di YANG, and Hong-tao WANG declare that they have no conflict of interest.

All institutional and national guidelines for the care and use of laboratory animals were followed.

\section{References}

An, L.N., Yue, Y., Guo, W.Z., et al., 2013. Surgical trauma induces iron accumulation and oxidative stress in a rodent model of postoperative cognitive dysfunction. Biol. Trace Elem. Res., 151(2):277-283.

http://dx.doi.org/10.1007/s12011-012-9564-9

Arora, S.S., Gooch, J.L., Garcia, P.S., 2014. Postoperative cognitive dysfunction, Alzheimer's disease, and anesthesia. Int. J. Neurosci., 124(4):236-242.

http://dx.doi.org/10.3109/00207454.2013.833919

Barres, B.A., 2008. The mystery and magic of glia: a perspective on their roles in health and disease. Neuron, $60(3)$ : 430-440. 
http://dx.doi.org/10.1016/j.neuron.2008.10.013

Cao, Y., Jiang, Z., Zeng, Z., et al., 2016. Bcl-2 silencing attenuates hypoxia-induced apoptosis resistance in pulmonary microvascular endothelial cells. Apoptosis, 21(1): 69-84. http://dx.doi.org/10.1007/s10495-015-1184-3

Guan, J.J., Zhang, X.D., Sun, W., et al., 2015. DRAM1 regulates apoptosis through increasing protein levels and lysosomal localization of BAX. Cell Death Dis., 6:e1624. http://dx.doi.org/10.1038/cddis.2014.546

Hernandez, R.V., Puro, A.C., Manos, J.C., et al., 2016. Transgenic mice with increased astrocyte expression of IL-6 show altered effects of acute ethanol on synaptic function. Neuropharmacology, 103:27-43. http://dx.doi.org/10.1016/j.neuropharm.2015.12.015

Jia, S.N., Lin, C., Chen, D.F., et al., 2016. The transcription factor $\mathrm{p} 8$ regulates autophagy in response to palmitic acid stress via a mammalian target of rapamycin (mTOR)independent signaling pathway. J. Biol. Chem., 291(9): 4462-4472. http://dx.doi.org/10.1074/jbc.M115.675793

Jin, W.J., Feng, S.W., Feng, Z., et al., 2014. Minocycline improves postoperative cognitive impairment in aged mice by inhibiting astrocytic activation. Neuroreport, 25(1):1-6.

Kim, G.H., Kim, J.E., Rhie, S.J., et al., 2015. The role of oxidative stress in neurodegenerative diseases. Exp. Neurobiol., 24(4):325-340. http://dx.doi.org/10.5607/en.2015.24.4.325

Li, R.L., Zhang, Z.Z., Peng, M., et al., 2013. Postoperative impairment of cognitive function in old mice: a possible role for neuroinflammation mediated by HMGB1, S100B, and RAGE. J. Surg. Res., 185(2):815-824. http://dx.doi.org/10.1016/j.jss.2013.06.043

Li, Y., Wang, S., Ran, K., et al., 2015. Differential hippocampal protein expression between normal aged rats and aged rats with postoperative cognitive dysfunction: a proteomic analysis. Mol. Med. Rep., 12(2):2953-2960.

Lu, J., Liu, Z., Xia, K., et al., 2015. Effect of preemptive analgesia with parecoxib sodium in patients undergoing radical resection of lung cancer. Int. J. Clin. Exp. Med., 8(8):14115-14118.

Pellerin, L., Bouzier-Sore, A.K., Aubert, A., et al., 2007. Activity-dependent regulation of energy metabolism by astrocytes: an update. Glia, 55(12):1251-1262. http://dx.doi.org/10.1002/glia.20528

Phillips, E.C., Croft, C.L., Kurbatskaya, K., et al., 2014. Astrocytes and neuroinflammation in Alzheimer's disease. Biochem. Soc. Trans., 42(5):1321-1325. http://dx.doi.org/10.1042/BST20140155

Pruchniak, M.P., Arazna, M., Demkow, U., 2016. Biochemistry of oxidative stress. Adv. Exp. Med. Boil., 878:9-19. http://dx.doi.org/10.1007/5584_2015_161

Rundshagen, I., 2014. Postoperative cognitive dysfunction. Dtsch. Arztebl. Int., 111(8):119-125.
Salloum, F.N., Hoke, N.N., Seropian, I.M., et al., 2009. Parecoxib inhibits apoptosis in acute myocardial infarction due to permanent coronary ligation but not due to ischemia-reperfusion. J. Cardiovasc. Pharmacol., 53(6): 495-498. http://dx.doi.org/10.1097/FJC.0b013e3181a7b5b6

Shen, L., Zhu, J., Chen, F., et al., 2015. RUNX1-Evi-1 fusion gene inhibited differentiation and apoptosis in myelopoiesis: an in vivo study. BMC Cancer, 15(1):970. http://dx.doi.org/10.1186/s12885-015-1961-y

Smith, C.C., Guevremont, D., Williams, J.M., et al., 2015. Apoptotic cell death and temporal expression of apoptotic proteins $\mathrm{Bcl}-2$ and $\mathrm{Bax}$ in the hippocampus, following binge ethanol in the neonatal rat model. Alcohol. Clin. Exp. Res., 39(1):36-44. http://dx.doi.org/10.1111/acer.12606

Takeda, K., Kermani, P., Anastasia, A., et al., 2013. BDNF protects human vascular endothelial cells from $\mathrm{TNF} \alpha-$ induced apoptosis. Biochem. Cell Biol., 91(5):341-349. http://dx.doi.org/10.1139/bcb-2013-0005

Valvassori, S.S., Arent, C.O., Steckert, A.V., et al., 2015. Intracerebral administration of BDNF protects rat brain against oxidative stress induced by ouabain in an animal model of mania. Mol. Neurobiol., 52(1):353-362. http://dx.doi.org/10.1007/s12035-014-8873-8

Yu, H.T., Zhen, J., Pang, B., et al., 2015. Ginsenoside Rg1 ameliorates oxidative stress and myocardial apoptosis in streptozotocin-induced diabetic rats. J. Zhejiang Univ.Sci. B (Biomed. \& Biotechnol.), 16(5):344-354. http://dx.doi.org/10.1631/jzus.B1400204

Zhang, N., Cheng, G.Y., Liu, X.Z., et al., 2014. Expression of $\mathrm{Bcl}-2$ and NF- $\kappa \mathrm{B}$ in brain tissue after acute renal ischemia-reperfusion in rats. Asian Pac. J. Trop. Med., 7(5): 386-389.

http://dx.doi.org/10.1016/S1995-7645(14)60061-4

\section{List of electronic supplementary materials}

Fig. S1 Identification of primary astrocytes using GFAP staining

\section{中文概要}

\section{题 目: 帕瑞昔布对过氧化氢诱导的原代星形胶质细胞} 氧化应激的保护作用

目 的: 评估帕瑞昔布对过氧化氢诱导的大鼠原代星形胶 质细胞氧化应激状态的保护作用, 并初步探讨其 作用机制。

创新点: 首次在大鼠原代星形胶质细胞中证实帕瑞昔布对 过氧化氢诱导的氧化应激具有保护作用, 且此作 用可能与 Bax、Bcl-2 和 BDNF 的失调有关。

方 法: 设立如下四组对照: (1) 阴性对照组; (2) $100 \mu \mathrm{mol} / \mathrm{L}$ $\mathrm{H}_{2} \mathrm{O}_{2}$ 处理组 (处理时间为 $24 \mathrm{~h}$ ) ; (3) $80 \mu \mathrm{mol} / \mathrm{L}$ 
帕瑞昔布处理组; （4） $160 \mu \mathrm{mol} / \mathrm{L}$ 帕瑞昔布处理 组 (第三和第四组先用帕瑞昔布处理 $24 \mathrm{~h}$, 再用 $100 \mu \mathrm{mol} / \mathrm{L} \mathrm{H}_{2} \mathrm{O}_{2}$ 处理 $24 \mathrm{~h}$ ）。用苂光显微镜观察 星形胶质细胞的形态, 用 MTT 法检测星形胶质 细胞的存活率, 用荧光探针二氯苂光黄双乙酸盐 (DCDHF-DA) 检测星形胶质细胞内氧自由基的 含量, 并用碘化丙啶 (PI) 染色检测细胞的调亡 状态。最后用反转录酶聚合酶链反应 (RT-PCR) 和蛋白质印迹（Western blot）检测 Bax、Bcl-2 和 BDNF 三种蛋白在 4 组中的表达水平。
结 论: $\mathrm{H}_{2} \mathrm{O}_{2}$ 处理可以导致星形胶质细胞的形态发生改 变 (图 1) 和存活率降低 (图 2), 提高星形胶 质细胞内的氧自由基水平（图 3)，同时诱导细 胞调亡 (图 4)。然而, 所有这些变化都可以被 帕瑞昔布逆转。此外, 我们发现, Bax、 $\mathrm{Bcl}-2$ 和 BDNF 的表达水平在 $\mathrm{H}_{2} \mathrm{O}_{2}$ 处理时失调, 而在帕 瑞昔布预处理时恢复正常。综上所述, 帕瑞昔布 对 $\mathrm{H}_{2} \mathrm{O}_{2}$ 诱导的氧化应激具有保护作用。

关键词：帕瑞昔布；原代星形胶质细胞；过氧化氢；Bax； Bcl-2; BDNF 